Article

\title{
Open Source Laser Polymer Welding System: Design and Characterization of Linear Low-Density Polyethylene Multilayer Welds
}

\author{
John J. Laureto ${ }^{1}$, Serguei V. Dessiatoun ${ }^{2}$, Michael M. Ohadi ${ }^{2}$ and Joshua M. Pearce ${ }^{1,3, *}$ \\ 1 Department of Materials Science and Engineering, Michigan Technological University, 601 M\&M Building, \\ 1400 Townsend Drive, Houghton, MI 49931-1295, USA; jjlauret@mtu.edu \\ 2 Smart and Small Thermal Systems Laboratory, Department of Mechanical Engineering, \\ University of Maryland, College Park, MD 20742, USA; ser@umd.edu (S.V.D.); ohadi@umd.edu (M.M.O.) \\ 3 Department of Electrical \& Computer Engineering, Michigan Technological University, Houghton, \\ MI 49931, USA \\ * Correspondence: pearce@mtu.edu; Tel.: +1-906-487-1466
}

Academic Editor: Xiaoliang Jin

Received: 26 May 2016; Accepted: 22 June 2016; Published: 1 July 2016

\begin{abstract}
The use of lasers to weld polymer sheets provides a means of highly-adaptive and custom additive manufacturing for a wide array of industrial, medical, and end user/consumer applications. This paper provides an open source design for a laser polymer welding system, which can be fabricated with low-cost fused filament fabrication and off-the-shelf mechanical and electrical parts. The system is controlled with free and open source software and firmware. The operation of the machine is validated and the performance of the system is quantified for the mechanical properties (peak load) and weld width of linear low density polyethylene (LLDPE) lap welds manufactured with the system as a function of linear energy density. The results provide incident laser power and machine parameters that enable both dual (two layers) and multilayer (three layers while welding only two sheets) polymer welded systems. The application of these parameter sets provides users of the open source laser polymer welder with the fundamental requirements to produce mechanically stable LLDPE multi-layer welded products, such as heat exchangers.
\end{abstract}

Keywords: polymer welding; laser welding; polymer laser welding; additive manufacturing; open hardware; linear low density polyethylene; LLDPE; heat exchangers

\section{Introduction}

Focused laser radiation absorbed into a polymer interface produces an elevated temperature, which can be used for inter-layer bonding. A contact free manufacturing method, such as laser welding, provides increased flexibility and further application than its conventional joint bonding processes [1]. Advancement in the field of polymer welding has expanded applications to microfluid polymer packages [2], aseptic packaging [3], hermetic sealing of an electronic car key [4], microfluidic channels [5], and additively manufactured and complex microchannel heat exchangers [6,7].

Characterization of polymer welds and in-process monitoring techniques have been explored with acoustic, optical, thermal, ultrasonic, and emission techniques $[8,9]$. Thus, the application of polymer sheet material(s) for lap-joint laser welding applications is not uncommon. Ghorbel et al. characterized the thermal and mechanical behavior of some thermoplastic polymers [10]. They successfully welded polypropylene sheets by diode-laser transmission welding [11] and selected soundness variables for the diode laser welding of polypropylene thermoplastic polymers by experimental and numerical analysis [12]. Also, Torrisi et al. characterized the adhesion susceptibility of polyethylene sheet materials $[13,14]$. The work described indicates that efficient welding of polymer materials is the result 
of not only thermally induced melting effects, but also the development of ions near the laser-polymer interface. Subsequently, pulsed laser radiation allows for adequate polymer weld adhesion, through photo-chemical and ion implantation effects, while not elevating the polymer beyond its melting temperature. All work described suggests that the resultant weld seam quality correlates to diode laser process parameters (laser power $(\mathrm{W})$ and cross-head speed $(\mathrm{mm} / \mathrm{s})$ ) and the optical/absorption properties of the incident polymer [11]. Dowding et al. successfully demonstrated the production of viable adhesive bonds between LLDPE (linear low density polyethylene) on PP (polypropylene) at an appropriate laser line energy $(\mathrm{J} / \mathrm{m})$, similar to a linear energy density (Coulombs $/ \mathrm{mm}$ ). In this study, maximum peel force was used for quantification [15]. The response behavior of the material system is constant in regard to incident laser line energy. Specifically, the linear energy density delivered to the polymer system requires, at a minimum, a critical value to induce bonding.

This paper provides open source designs for a laser polymer welding system and then explores the mechanical properties and weld width appearance of LLDPE lap welds manufactured with the system. Specifically, apparent peak load (lbf) and linear energy density (coulombs $/ \mathrm{mm}$ ), corresponding to weld width $(\mathrm{mm})$, are quantified. The designed, open-source, system is meant to provide a reliable manufacturing tool to be readily adapted to a multitude of polymer welding applications. Available source code and the provided component build files allow a multitude of users the ability to utilize the technology as they see appropriate.

\section{Materials and Methods}

\subsection{Laser Welder}

An open-source computer numeric control (CNC) laser welder [16] was modified for this experiment. The apparatus is a gantry device with NEMA17 motors driving 20 tooth GT2 pulleys, one set for the $x$-axis and one for $y$. The frame is constructed with 20-20 extruded aluminum with accommodating fittings and fixtures. Utilized bearings and guide rods are readily available standard equipment for purchase.

Printed members (Table 1) were redesigned in OpenSCAD [17], an open source parametric scripting computer aided design (CAD) program, and printed on a standard RepRap [18-21] using polylactic acid (PLA). Parts were designed so as to maximize rigidity while minimizing plastic consumption to minimize printing time, embodied energy, environmental impact, and economic cost. All SCAD files are available for free [22] under the GNU GPLv3 [23] along with operational instructions [24].

Boxed idler ends were designed to maximize rigidity and to assure proper belt tracking under tension. $624-\mathrm{ZZ}$ roller bearings on $4 \mathrm{~mm}$ shafts were used as idlers. Belt tension was applied and maintained through the use of large nylon wire ties stretched between belt terminators previously designed for the MOST delta RepRap [25].

The $\mathrm{x}$-carriage can adjust the position of the laser in the z-direction to assist in focusing. A pair of printed thumbscrews clamp the position of a threaded rod upon which they ride to the $\mathrm{x}$-carriage. The laser mount is fixed to one end of the threaded rod and additionally constrained in the $x$ and $\mathrm{y}$-directions by a $6 \mathrm{~mm}$ smooth rod that is press-fit into the mount and passes through the $\mathrm{x}$-carriage. The assembled $x$-carriage and z-adjustment system are shown in Figure 1.

Mechanical snap-action switches to eliminate the need for a $5 \mathrm{~V}$ power supply and to simplify the design. A Melzi controller [26] was mounted to the frame with three dimensional (3-D) printed components and this is driven by a Raspberry Pi [27] with custom Franklin firmware [28,29], Arroyo Instruments 432020 A LaserSource, and 5305 5A/12V TECSource. Gcode, for the laser profile scans, was user-generated and imported into Franklin. As designed, the 432020 A LaserSource and X/Y laser-head movement is controlled by commands the user prescribed, while the 5305 TECSource is a standalone unit. The 432020 A LaserSource provides the incident laser source while the 5305 TECSource is the cooling system for the laser apparatus. 
Table 1. Three-dimensional (3-D) printed parts.

\begin{tabular}{|c|c|c|c|c|c|}
\hline Part Name/Description & Count & Rendered Image & Part Name/Description & Count & Rendered Image \\
\hline $\begin{array}{l}\text { Controller standoff for } \\
\text { attaching controller } \\
\text { to frame }\end{array}$ & 1 & 1. & $\begin{array}{l}\text { Laser carriage for } \\
\text { mounting laser to } \\
\text { holder apparatus }\end{array}$ & 1 & \\
\hline $\begin{array}{l}\text { Limit switch mount for } \\
\text { mechanical switches to } \\
\text { appropriate guide rods }\end{array}$ & 2 & & $\begin{array}{l}\text { M8 thumbscrew for } \\
\text { adjusting z-position of } \\
\text { laser carriage }\end{array}$ & 2 & \\
\hline $\begin{array}{l}\text { X-carriage cable mount } \\
\text { for attaching a cable } \\
\text { carrier to the x-carriage }\end{array}$ & 1 & & $\begin{array}{l}\text { X-carriage for } \\
\text { connecting } x \text {-axis linear } \\
\text { bearings to } x \text {-axis drive } \\
\text { belt, laser carriage, and } \\
\text { cable carrier }\end{array}$ & 1 & \\
\hline $\begin{array}{l}\text { X-clamp for securing } \\
\text { x-axis guide rods to } \\
y \text {-bearings and for } \\
\text { holding } x \text {-axis idler }\end{array}$ & 2 & & $\begin{array}{l}\mathrm{X} \text { fixed cable carrier } \\
\text { mount for attaching } \\
\text { cable carrier } \\
\text { to y-bearing }\end{array}$ & 1 & \\
\hline $\begin{array}{l}\text { X-idler cap for boxing } \\
\text { x-axis idler bearing } \\
\text { and shaft }\end{array}$ & 1 & & $\begin{array}{l}\text { X-motor mount for } \\
\text { mounting x-motor } \\
\text { to y-bearing }\end{array}$ & 1 & \\
\hline $\begin{array}{l}\text { X-motor saddle cable } \\
\text { carrier mount for } \\
\text { mounting a cable } \\
\text { carrier for the y-axis } \\
\text { and for added rigidity } \\
\text { of the x-motor mount }\end{array}$ & 1 & & $\begin{array}{l}\text { Y cable mount for } \\
\text { mounting fixed end of } \\
\text { y-axis cable carrier }\end{array}$ & 1 & \\
\hline $\begin{array}{l}\text { Y-carriage for } \\
\text { connecting y-bearing to } \\
\text { y-drive belt }\end{array}$ & 1 & & $\begin{array}{l}\text { Y-idler for holding } \\
\text { y-axis idler bearing }\end{array}$ & 2 & \\
\hline $\begin{array}{l}\text { Y-motor mount for } \\
\text { attaching y-motor } \\
\text { to frame }\end{array}$ & 1 & & $\begin{array}{l}\text { Fixed belt terminator } \\
\text { for attaching drive belt } \\
\text { to } x \text { and y-carriages and } \\
\text { tensioning of open } \\
\text { ended belting }\end{array}$ & 2 & 8 \\
\hline $\begin{array}{l}\text { Free belt terminator for } \\
\text { tensioning of open } \\
\text { ended belting }\end{array}$ & 2 & 2 & - & - & - \\
\hline
\end{tabular}

Cable carriers are used to support the laser fiber and were mounted such that the fiber is nearly continuously protected. The laser source is positioned under the frame. The entire apparatus (Figure 2) is placed in a shielded aluminum box for the safety of operators.

\subsection{Materials}

Liner low-density polyethylene (LLDPE), which is typically utilized as an underground encasement of ductile iron pipes per ANSI/AWWA C105/A21.5, is analyzed. Large industrial LLDPE rolls are readily available [30]. Material was obtained in a continuous length measuring 
16 in $(406.4 \mathrm{~mm}) \pm 0.5 \mathrm{in}(12.7 \mathrm{~mm})$ in width and manufactured to a minimum thickness of 0.008 in $(0.203 \mathrm{~mm})$. The supplier's technical data sheets indicate a density of 0.910 to $0.935 \mathrm{~g} / \mathrm{cm}^{3}$ and a carbon black additive of no less than $2 \%$ [31].

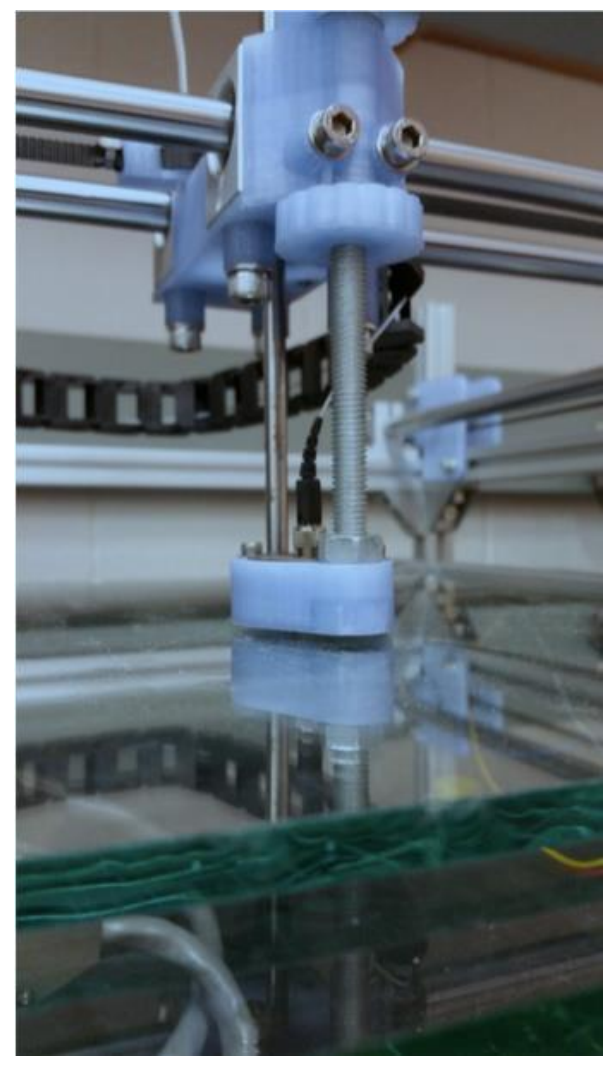

Figure 1. Closeup of the $\mathrm{x}$-carriage $\mathrm{z}$-axis adjustment assembly.

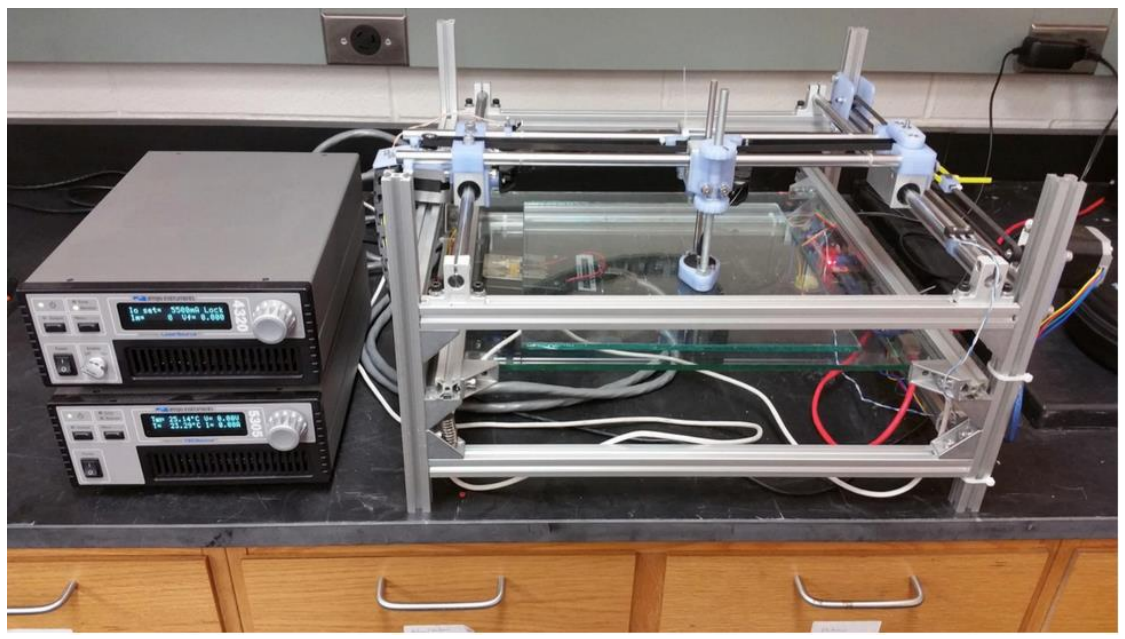

Figure 2. Completed open-source laser welder apparatus.

\subsection{Fabrication}

The LLDPE sheeting was sectioned into dimensions $2.25 \times 4.5$ in $(57.15 \times 114.3 \mathrm{~mm}) \pm 0.5$ in $(12.7 \mathrm{~mm})$. The specified dimensions allow for sufficient bonding area to be analyzed while fitting into the tensile testing grips used for analysis. Prior to all welding operations, foreign particulate (e.g., dust 
and debris) was removed from the surface with a wet cloth then allowed to dry. Contaminates, as described, may depreciate the validity of the analysis.

A single sample component is comprised of two to three layers of LLDPE, to dimensions specified prior, depending upon testing conditions. Three individual samples are placed inside the polymer welder at a time, thus providing three samples per testing condition. Multiple testing conditions were analyzed beyond variable layer count. Incident current (I) and cross-head speed were intentionally varied throughout the analysis. Specifically, the incident current was incremented $0.5 \mathrm{~A}$ per analysis within the range of $5 \mathrm{~A}-20 \mathrm{~A}$, and all collected data was done in two scenarios: one using a $10 \mathrm{~mm} / \mathrm{s}$ cross-head speed, and the other using a $20 \mathrm{~mm} / \mathrm{s}$ cross-head speed. Laser scan patterns proceeded linearly across the sample component, parallel to the rolled direction, near mid length $\sim 2.25$ in $(57.15 \mathrm{~mm})$. Table 2 describes the test parameters in further detail.

Table 2. LaserSource 20A 4320 Set Up Values.

\begin{tabular}{ccc}
\hline Variable & Value & Units \\
\hline Mode & $\mathrm{I}_{\mathrm{o}}(\mathrm{ACC})$ & - \\
$\mathrm{I}_{\mathrm{o}}$ Limit ${ }^{1}$ & $5.5-20$ & Amps $(\mathrm{A})$ \\
$\mathrm{I}_{\mathrm{m}}$ Limit & 20,400 & Microamps $(\mu \mathrm{m})$ \\
$\mathrm{V}_{\mathrm{f}}$ Limit & 5.1 & Volts $(\mathrm{V})$ \\
$\mathrm{V}_{\mathrm{f}}$ Sense & Internal & - \\
Cable $\mathrm{R}$ & 0.0 & Ohms $(\Omega)$ \\
Tolerance $\mathrm{I}_{\mathrm{o}}$ & 100 & Milliamps $(\mathrm{mA})$ \\
On Delay & 0.0 & Milliseconds $(\mathrm{ms})$ \\
\hline \multicolumn{3}{c}{${ }^{1}$ Variable in experimentation. }
\end{tabular}

Low-iron glass plates, $0.6 \mathrm{~cm}$ thick, were utilized to ensure sample stability and flatness during the welding operation. The experimental setup involved layering three samples adjacent to one another, along their $4.5 \mathrm{~mm}$ length, followed by another secondary low-iron glass plate placed on top. Second, the laser head, modifiable with a set screw, was placed adjacent to the top glass surface. Figure 3 describes the set-up involved during all experimentation.

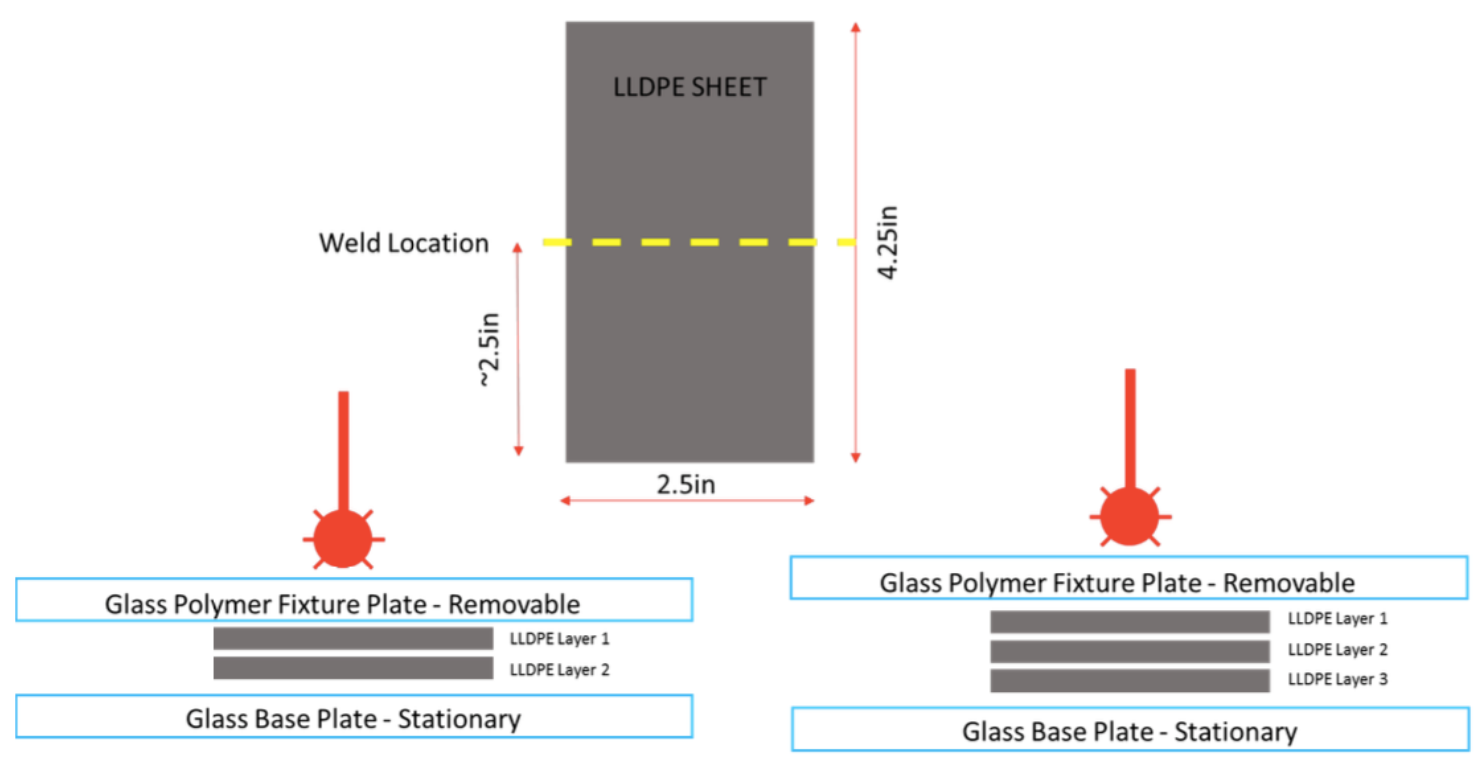

Figure 3. Sample dimensions and two/three layer experimental set up. Linear low density polyethylene (LLDPE), linear low density polyethylene. 


\subsection{Characterization}

\subsubsection{Peak Load Determination}

Procured materials for this analysis are assumed to not be anisotropic. Specifically, all tensile tests performed induce force normal to the rolled direction of the manufactured LLPDE and/or normal to the weld line. Baseline analysis of "virgin" LLDPE samples (e.g., no weld line specimens) can be directly compared to their welded counterparts. An Instron 4206 tensile tester with testing procedures modeled after ASTM D2990-01 and D638-02a allowed for determination of peak load (lbf) for all sample conditions [32,33]. Specimens comprised of two and three layers were subjected to this analysis. All two layered components exhibiting adequate layer-to-layer adhesion were deemed adequate. If visual analysis post-welding determined any delamination and/or lack of weld cross section, the sample was omitted from the analysis. Similar inspection criteria were employed on the three layer samples. Ideally, the bottom layer (third layer-Figure 3) will not bond to the near-adjacent first and second layers, which enables complex 3-D geometries to be fabricated with this system (e.g., heat exchangers). Thus, the near-adjacent layers can be welded independently of the previous bottom layers of LLDPE. Fabrication methods, as described prior, are aimed to ensure this. Thus, tensile testing on three layered specimens was performed pending the observation that the first and second layers are adequately bonded while the third has not.

\subsubsection{Weld Width (mm) and Resultant Energy Density (Coulombs $/ \mathrm{mm}$ )}

The application of imaging software ImageJ 1.49 [34] allowed for the quantitative analysis of each respective weld width. Images selected for analysis were captured utilizing a standard digital camera. The image frame (i.e., contained in the image(s)) were a representative top-down view of each weld line. Each image frame contained a ruler with 0.5 and $1.0 \mathrm{~mm}$ resolution/gradations. The ruler provided the ability to utilize ImageJ 1.49 to properly scale the captured images. This is accomplished by the software measurement correlation to the "real" measurements using a "pixels/in" determination. An average of three distinct line profile length measurements ensured statistical confidence in operator measurement(s). Figure 4 displays a representative weld width photograph used for width determination.

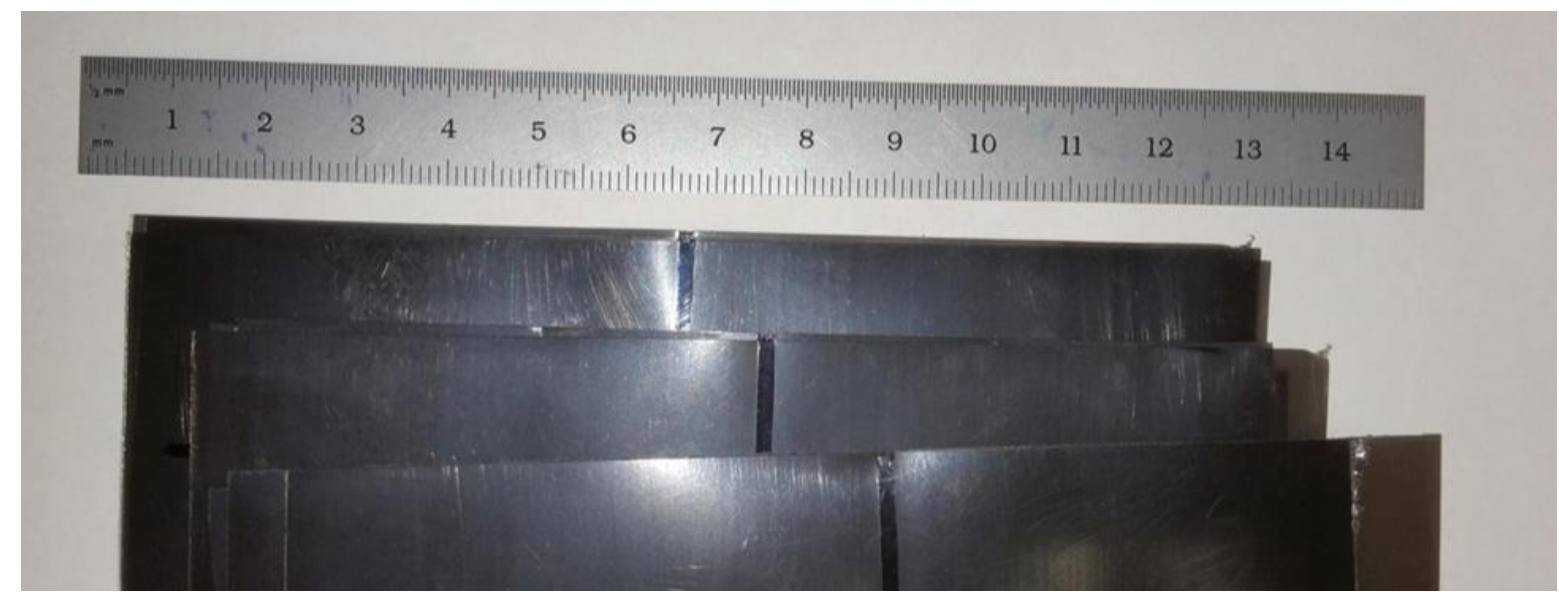

Figure 4. Representative weld width analysis photograph.

Correlating laser cross-head speed to incident laser current derives an expression for linear energy density (Coulombs (A.s)/mm). Thus, linear energy density, weld width, and peak load can be characterized. 


\section{Results}

\subsection{Weld Width at Various Linear Energy Densities}

Linear regression analysis of measured weld width vs. linear energy density data show that weld width increases with increased linear energy density. Figures 5-8 describe the correlation. Directly comparing the regression analysis of Figures 5 and 7 (two layered systems) shows that the slopes are near equivalent and greater than one. Conversely, Figures 6 and 8 (three layered systems) also display a similar slope, although at a different magnitude of $\sim 0.5$. Weld width data was recorded for linear welds with, at a minimum, incident laser appearance. Specifically, solid linear welds to observable faint heat lines were recorded. Significant data spread, in reference to the trend line, is apparent in Figure 5 at a range of 0.5-1.3 (Coulombs $/ \mathrm{mm}$ ). At relatively low linear energy densities the resultant weld width is a gradient (e.g., a thin linear indication that gradually fades at distances normal to the weld direction). Conversely, relatively high linear energy density welds develop weld seams with a visible finite width. Thus, upon measurement with ImageJ, the identification of the apparent weld is subjective as some zone within the gradient is selected as the edge. The deviation in operator measurement, which is identified as the edge of the weld, causes the spread shown in the Figure 5 data set.

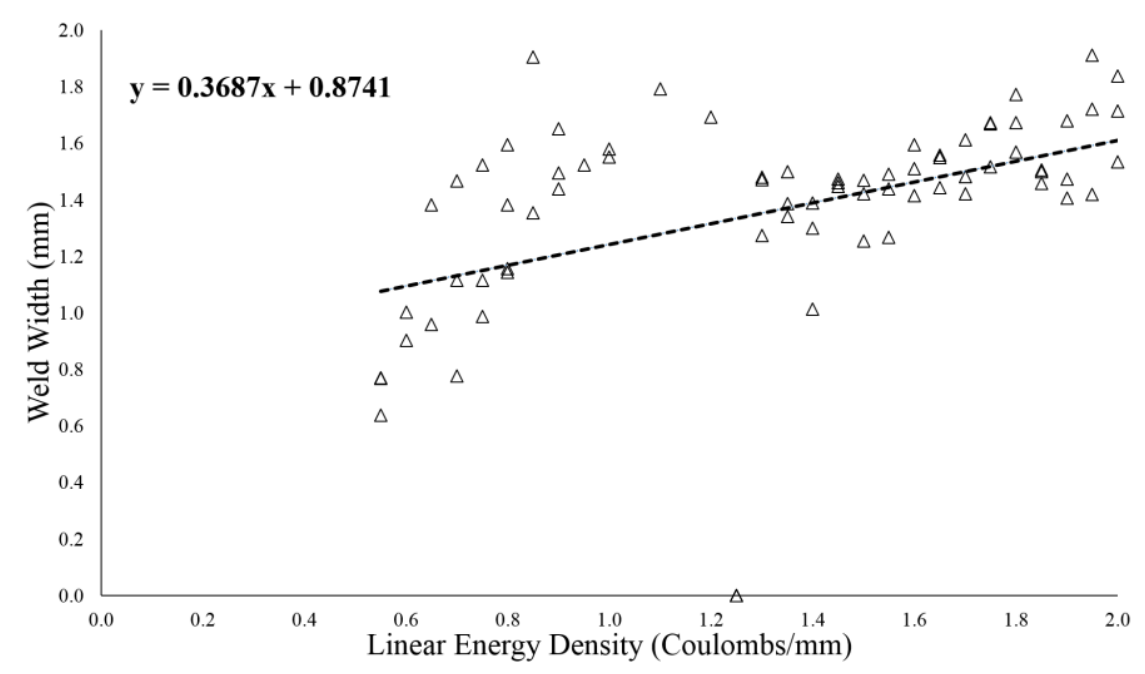

Figure 5. Weld width as a function of linear energy density for $10 \mathrm{~mm} / \mathrm{s}$ on two layers of LLDPE.

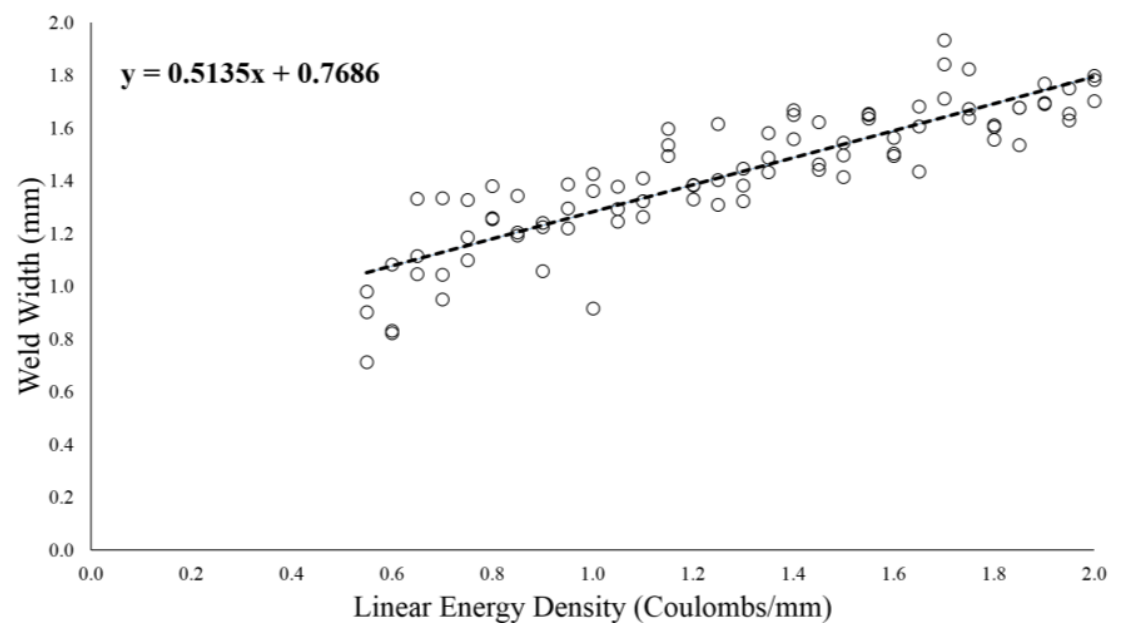

Figure 6. Weld width as a function of linear energy density for $10 \mathrm{~mm} / \mathrm{s}$ on three layers of LLDPE. 


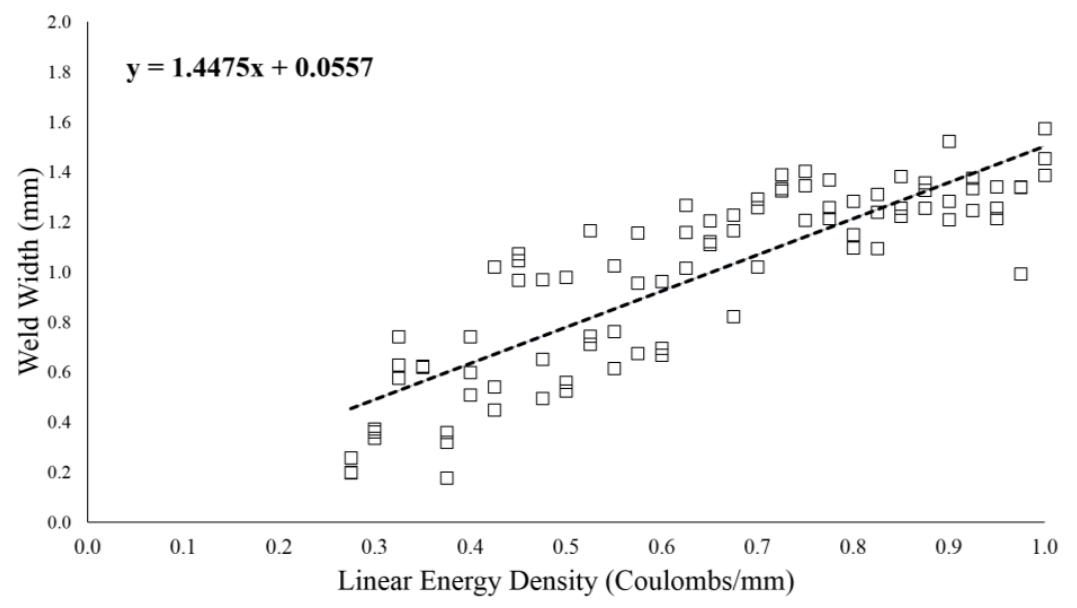

Figure 7. Weld width as a function of linear energy density for $20 \mathrm{~mm} / \mathrm{s}$ on two layers of LLDPE.

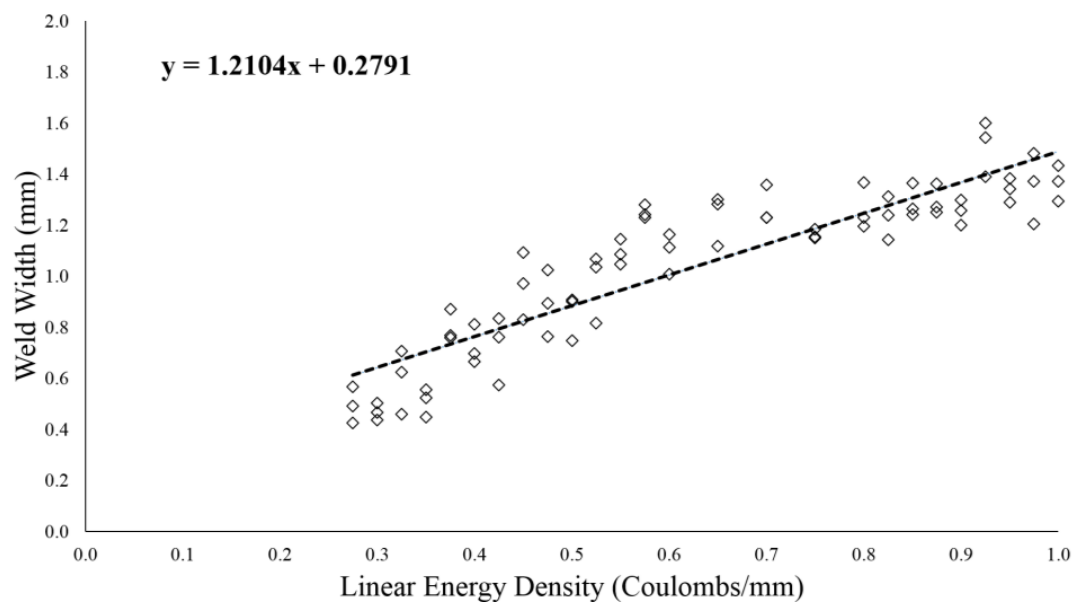

Figure 8. Weld width as a function of linear energy density for $20 \mathrm{~mm} / \mathrm{s}$ on three layers of LLDPE.

Typical weld cross sections are as shown in Figures 9 and 10. Figure 9 demonstrates a quality weld, while Figure 10 demonstrates a delaminated failed weld.

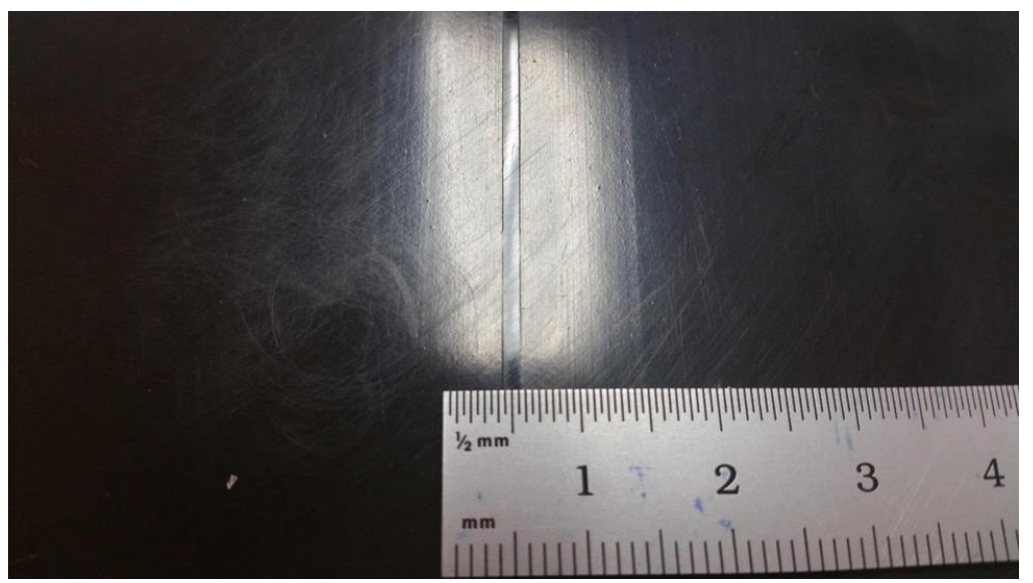

Figure 9. Representative photograph of a quality two layer LLDPE polymer laser weld. Similar surface topology, as shown, is apparent in three layer LLDPE weld systems. 


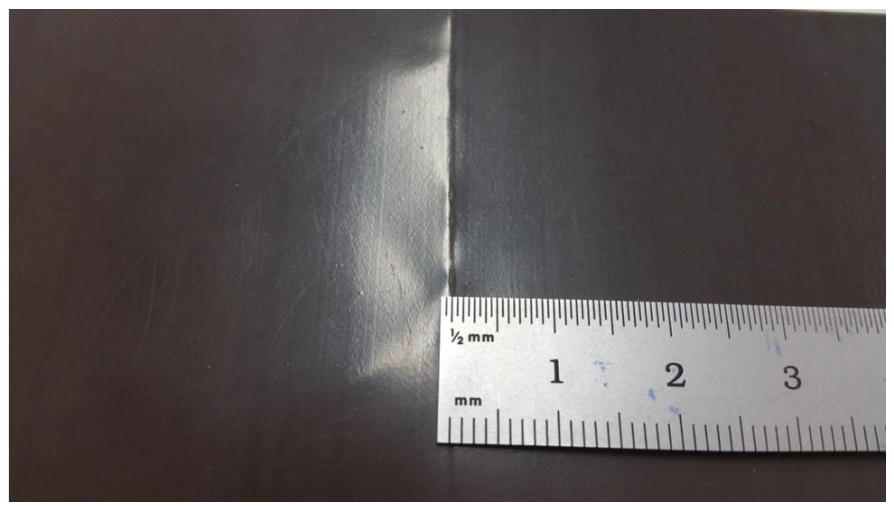

Figure 10. Representative photograph of a degraded two layer LLDPE polymer laser weld. Similar line width decrease is apparent in three layer LLDPE weld systems.

\subsection{Polymer Weld Adhesion of Two and Three Layered LLDPE Systems Available}

Adhesion susceptibility due to an increase in linear energy density was analyzed qualitatively. Post welding operations/attempts, operators would analyze generated welds and exert a small pull force (by hand) in attempts to shear the weld zone. Welds requiring minimal effort (e.g., tackiness) were deemed unacceptable for further analysis. Welds exhibiting greater adhesion (i.e., greater than minimal force) were subjected to further mechanical testing. Laser welds requiring further mechanical testing and those sheared are shown in Figures 10 and 11, respectively. The linear line indication in Figures 11 and 12 represent solid weld regions. A proper weld contains a solid line (Figure 11). Conversely, a poor weld (Figure 12) will have dashed indications displaying improper adhesion. It is to be concluded that the ideal weld appearance will be a solid uninterrupted line.

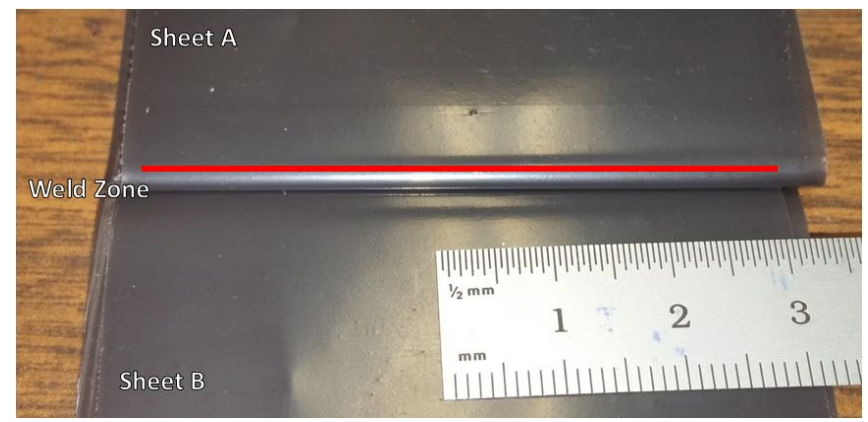

Figure 11. Laser weld subjected to further mechanical testing. Linear indications signify proper adhesion at the weld interface of the LLDPE sheeting.

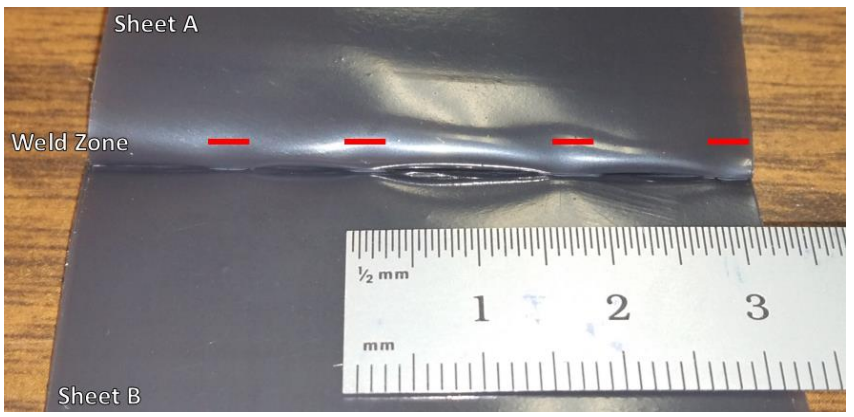

Figure 12. Laser weld not subjected to further mechanical testing. Broken/dashed linear indication represented a degraded weld seam between the LLDPE sheeting. 
Figure 13 describes each testing scenario and their respective shear point(s) (e.g., where mechanical testing is not required for quantification).

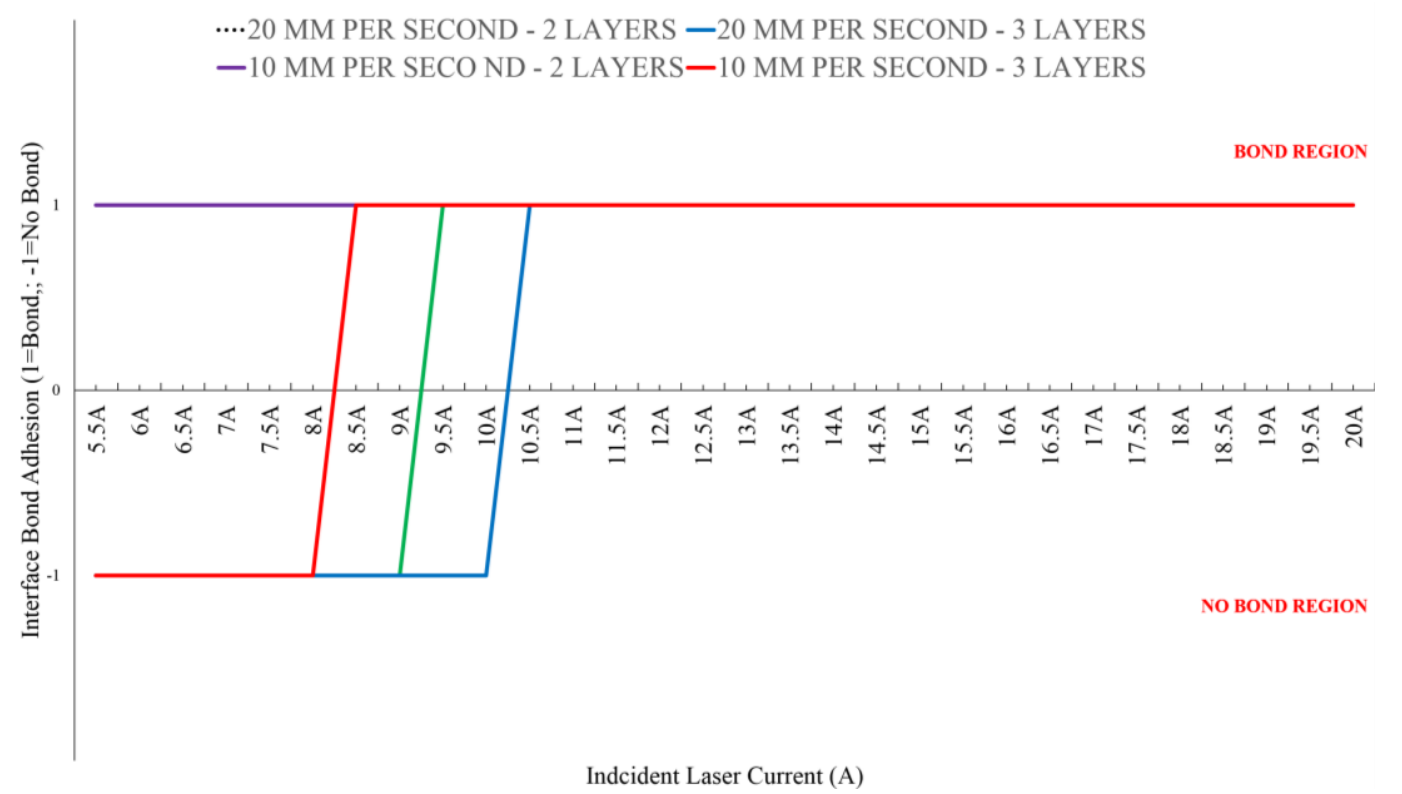

Figure 13. Shear and Bond Zone comparisons of 10 and $20 \mathrm{~mm} / \mathrm{s}$ cross-head speeds at variable incident laser current (A).

In application of three layered based systems a delaminated (i.e., un-bonded) third layer is ideal. Specifically, the information described in Figure 13 indicates that multilayered systems are applicable to this technology. By proper control of the linear energy density (vector speed $\mathrm{x}$ incident current (i.e., laser power)) the overall depth of penetration can be controlled. Thus, providing an adequate system to develop multichannel and multi-layered laser welded LLDPE polymer systems. Specifically, in the developed system for three layered manufacturing processes at 10 and $20 \mathrm{~mm} / \mathrm{s}$ are to be set at 8.5 and $10.5 \mathrm{~A}$, respectively. At these specified zones, the laser system has successfully welded two layers of the three layered systems. Amperage settings greater than those recommended will yield completely welded three layered components. Conversely, amperages settings below the recommendations may fail to allow the top two layers to bond.

\subsection{Mechanical Testing-Peak Load (lbf)}

Mechanical testing was performed on all sample components abiding similar criteria, to the energy density determination, were met. Typically, recorded mechanical data is resultant of an average of three different peak load determinations. Specifically, all mechanically tested samples resemble those described in Figure 11. Raw (i.e., non-welded LLDPE) samples set the baseline for the analysis. Maximum sustained peak loads for each experimental condition (10 mm/s-two layers, $10 \mathrm{~mm} / \mathrm{s}$ - three layers, $20 \mathrm{~mm} / \mathrm{s}$-two layers, and $20 \mathrm{~mm} / \mathrm{s}$-three layers) are displayed in Table 3. Representative values shown indicate maximum peak load at the experimental setting just after the shear zone (no-bond region). Thus, any incident current greater than the critical shear zone limit amperage will provide, at a minimum, this corresponding peak load. Furthermore, for comparative purposes, typical load-extension curves are displayed in Figure 14. Samples were subjected to a cross-head displacement rate of $1 \mathrm{in} / \mathrm{min}$ with the maximum allowable extension set at $1 \mathrm{in}$. The test was completed if a break/rupture was measured and/or the maximum cross-head displacement was reached. 


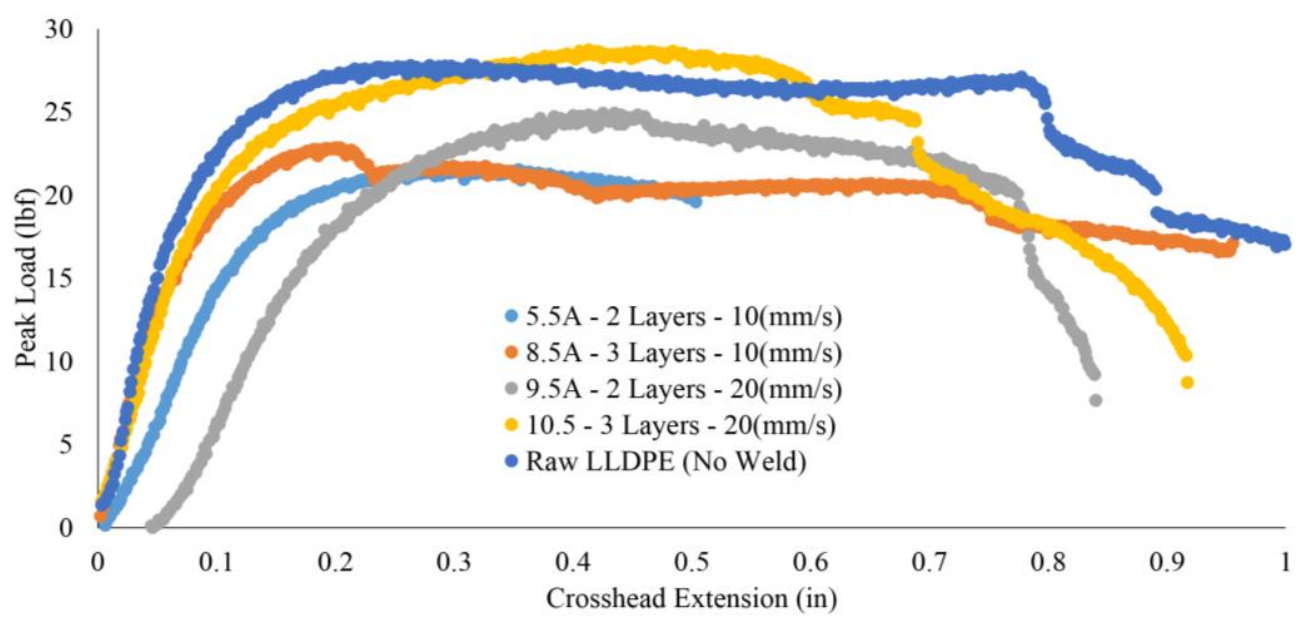

Figure 14. Typical load-elongation curves for sample conditions described in Table 3. Samples were subjected to a cross-head displacement of $1 \mathrm{in} / \mathrm{min}$.

Table 3. Maximum sustained peak load above shear point of LLDPE weld(s).

\begin{tabular}{ccccc}
\hline Sample Material & Condition/Speed $(\mathbf{m m} / \mathbf{s})$ & LLDPE Layers & Peak Load $( \pm \boldsymbol{\sigma}) \mathbf{( l b f )}$ & Incident Current Setting (A) \\
\hline LLDPE & RAW & - & $26.6(2.1)$ & - \\
LLDEP & 10 & 2 & $19.6(3.8)$ & 5.5 \\
LLDPE & 10 & 3 & $25.3(3.4)$ & 8.5 \\
LLDPE & 20 & 2 & $25.7(1.4)$ & 9.5 \\
LLDPE & 20 & 3 & $25.4(2.8)$ & 10.5 \\
\hline
\end{tabular}

\section{Discussion}

The proposed welding system was shown to adhere multi-layered systems. Sustained peak load measurements of the resultant weld width(s) are equivalent to a virgin/raw LLDPE sample sheet. The experimental trials have identified shear zones of the particular weld systems (e.g., 10 and $20 \mathrm{~mm} / \mathrm{s}$ cross-head speeds coupled with variable incident beam current). Quantification of the rigidity of two layered LLDPE systems, specifically the shear zone, allows for confirmation of a quality lap weld seam. Furthermore, shear zone identification in three layered systems determines the appropriate linear energy density for a given multi-layered system.

Mechanical property results describe a system in which a welded interface will perform similarly to that of its not welded raw/virgin counterpart. Comparison of the representative data in Table 3 shows, at a maximum, the overall degradation in sustain peak load (lbf) is $26.32 \%$ ( $10 \mathrm{~mm} / \mathrm{s}$ and two layers of LLDPE). Collected mechanical data (peak load (lbf)) is representative of a weld just beyond the potential shear zone. These data points described are theoretical operating minimums of the polymer welding system. Thus, an adequate safety factor is to be applied to further manufacturing operations to ensure, at a minimum, the peak load of the theoretical minimum is achieved. For example, in a three layer $20 \mathrm{~mm} / \mathrm{s}$ condition the incident current setting should be $10 \%-20 \%$ larger than the recommended minimums of $9.5 \mathrm{~A}$. The clustering of the mechanical property results suggest that a weld interface does not significantly impact the mechanical performance of the polymer in this test scenario. Various energy densities have been shown to produce quality welds. Refer to Table 3 , a LLDPE polymer weld at $10 \mathrm{~mm} / \mathrm{s}$ with 8.5 A current $(0.425$ Coulombs $/ \mathrm{mm})$ produces a peak sustained load of $25.3 \mathrm{lbf}$. Comparatively, a LLDPE polymer weld at $20 \mathrm{~mm} / \mathrm{s}$ with $10.5 \mathrm{~A}$ current $(0.525$ Coulombs $/ \mathrm{mm}$ ) produced a peak load of $25.4 \mathrm{lbf}$. Therefore, a linear energy variance of $21.95 \%$ produces a LLDPE weld seam where the average mechanical property variance is relatively small at $0.39 \%$.

Larger scaled application(s) are possible with large X-Y build platforms. Increased productivity (i.e., speed of manufacturing) is achievable by implementation of multiple laser head systems. 
Situations and models described in these experiments utilize a single laser source head, whereas multiple systems would allow for a similar part (laser paths) to be replicated during the same manufacturing cycle. Similarly, increased laser power allows for increased manufacturing speed [35]. High power laser systems have been shown to be valuable in the current scope in laser welding applications [4]. Thus, quick-high power systems are achievable. In addition, large-scale mass manufacturing is possible with this process using roll-to-roll technology [7].

Furthermore, numerous direct applications are available for implementation of the proposed system. For example, the system can be used for additive manufacturing of vehicle heat recovery ventilators for the automotive industry [36], industrial heat exchangers [6,37], heat exchangers for solar water pasteurization [38], hermetic thermoplastic medical device encapsulation [39], bio-microfluidic channels in transparent polymer materials [40], and consumer goods packaging [41]. The polymer laser welder described is ideal for rapid prototyping. For example, the new floating photovoltaics (FPV) can be combined with aquaponics to makeaquavoltaics (AV), which use thin film flexible substrate based solar photovoltaic (PV) modules to float on water, yet designs have largely been untested [42,43]. The low mass allows a significantly diminished supporting structure and the flexible nature of the system allows for designed yield to oncoming waves while maintaining electrical performance [44]. This enables FV to take advantage of the superior net energy production of thin film PV materials like amorphous silicon $[45,46]$. To maintain the flexibility and long term structural integrity of the module, thin-films should be encapsulated by a polymer with high transparency, low rigidity, and be waterproof [42], and during the encapsulation process air pockets or voids can be purposefully introduced to increase buoyancy without increasing mass [44]. The system described in this article can be used to test various thin-film FPV designs by prototyping them at minimal costs.

\section{Conclusions}

Modification of a standard RepRap system has allowed for the development of a novel laser welding system and weld protocol. Previously custom developed Franklin firmware has provided an intuitive graphical user interface in which to control the welding system. Mechanical property analysis and weld width characterization of representative LLDPE polymer welds have shown applicability to multiple industrial, medical, and end user/consumer systems. Results have shown success in both dual (two layer) and multilayer (three layer) systems. Proper incident laser power and machine parameters (i.e., linear energy density) have been determined. Application of these parameter sets will provide user(s) with the fundamental LLDPE requirements to produce adequate mechanical polymer welds. Incident laser current (A) has been shown to display a positive linear relationship with relative weld width data. Thus, weld width increases as incident laser current increases. However, increased laser current did not show any increase and/or degradation to the LLDPE weld mechanical properties.

Acknowledgments: Financial support of this work by U.S. Department of Energy ARPA-e, Award \# DE-AR0000507 is greatly acknowledged. The authors would also like to acknowledge technical assistance from Gerald Anzalone and Paul Fraley and helpful discussions with David Denkenberger, James Klausner, and Geoffery Short.

Author Contributions: J.L. performed all polymer welding experimentation, including data analysis and interpretation. S.V.D. provided guidance and materials selection. M.M.O. led the project and overall collaborative effort of all entities. J.M.P. conceived of the application and development of the designs and the experiments, and helped analyze the data. All authors were responsible for writing and editing the final manuscript.

Conflicts of Interest: The authors declare no conflict of interest.

\section{References}

1. Becker, F.; Potente, H. A step towards understanding the heating phase of laser transmission welding in polymers. Polym. Eng. Sci. 2002, 42, 365-374. [CrossRef]

2. Garst, S.; Schuenemann, M.; Solomon, M.; Atkin, M.; Harvey, E. Fabrication of multilayered microfluidic 3D polymer packages. Proc. Electron. Compon. Technol. 2005, 1, 603-610. 
3. Brown, N.; Kerr, D.; Jackson, M.; Parkin, R. Laser welding of thin polymer films to container substrates for aseptic packaging. Opt. Laser Technol. 2000, 32, 139-146. [CrossRef]

4. Bachmann, F. Industrial applications of high power diode lasers in materials processing. Appl. Surf. Sci. 2003, 208-209, 125-136. [CrossRef]

5. Tsao, C.-W.; DeVoe, D.L. Bonding of thermoplastic polymer microfluidics. Microfluid. Nanofluid. 2009, 6, 1-16. [CrossRef]

6. Arie, M.A.; Tiwari, R.; Shooshtari, A.H.; Dessiatoun, S.V.; Ohadi, M.M.; Pearce, J.M. Experimental Characterization of Heat Transfer in an Additively Manufactured Polymer Heat Exchanger. 2016, under review.

7. Denkenberger, D.C.; Brandemuehl, M.J.; Pearce, J.M.; Zhai, J. Expanded microchannel heat exchanger: Design, fabrication, and preliminary experimental test. Proc. Inst. Mech. Eng. Part A J. Power Energy 2012, 226, 532-544. [CrossRef]

8. Shao, J.; Yan, Y. Review of techniques for on-line monitoring and inspection of laser welding. J. Phys. Conf. Ser. 2005, 15, 101-107. [CrossRef]

9. Norman, P.; Engström, H.; Kaplan, A.F.H. Theoretical analysis of photodiode monitoring of laser welding defects by imaging combined with modelling. J. Phys. D Appl. Phys. 2008, 41, 195502. [CrossRef]

10. Ghorbel, E.; Hadriche, I.; Casalino, G.; Masmoudi, N. Characterization of thermo-mechanical and fracture behaviors of thermoplastic polymers. Materials 2014, 7, 375-398. [CrossRef]

11. Ghorbel, E.; Casalino, G.; Abed, S. Laser diode transmission welding of polypropylene: Geometrical and microstructure characterisation of weld. Mater. Des. 2009, 30, 2745-2751. [CrossRef]

12. Hadriche, I.; Ghorbel, E.; Masmoudi, N.; Casalino, G. Investigation on the effects of laser power and scanning speed on polypropylene diode transmission welds. Int. J. Adv. Manuf. Technol. 2010, 50, 217-226. [CrossRef]

13. Torrisi, L.; Caridi, F.; Visco, A.M.; Campo, N. Polyethylene welding by pulsed visible laser irradiation. Appl. Surf. Sci. 2011, 257, 2567-2575. [CrossRef]

14. Torrisi, L.; Visco, A.M.; Campo, N.; Caridi, F. Pulsed laser treatments of polyethylene films. Nucl. Instrum. Methods Phys. Res. Sect. B Beam Interact. Mater. Atoms 2010, 268, 3117-3121. [CrossRef]

15. Dowding, C.; Dowding, R.; Franceschini, F.; Griffiths, J. The effect of laser power, traverse velocity and spot size on the peel resistance of a polypropylene/adhesive Bond: Non-contact laser based technique of polymer bonding. Packag. Technol. Sci. 2015, 28, 621-632. [CrossRef]

16. Pearce, J.M. Open-Source Lab: How to Build Your Own Hardware and Reduce Research Costs; Elsevier: Waltham, MA, USA, 2014.

17. OpenSCAD. Available online: http://www.openscad.org/ (accessed on 21 April 2016).

18. Jones, R.; Haufe, P.; Sells, E. Reprap-The replicating rapid prototype. Robotica 2011, 29, 177-191. [CrossRef]

19. Bowyer, A. 3D printing and humanity's first imperfect replicator. 3D Print. Addit. Manuf. 2014, 1, 4-5. [CrossRef]

20. Sells, E.; Bailard, S.; Smith, Z.; Bowyer, A.; Olliver, V. RepRap: The replicating rapid prototyper-maximizing customizability by breeding the means of production. In Handbook of Research in Mass Customization and Personalization, Volume 1: Strategies and Concepts; Pillar, F.T., Tseng, M.M., Eds.; World Scientific: Hackensack, NJ, USA, 2009; pp. 568-580.

21. Rundle, G.A. Revolution in the Making: 3D Printing, Robots and the Future; Affirm Press: South Melbourne, Australia, 2014.

22. Open Science Framework. Available online: https://osf.io/r7hn6/ (accessed on 11 April 2016).

23. GNU Operating System. Available online: http://www.gnu.org/licenses/gpl-3.0.en.html (accessed on 22 May 2016).

24. Laser Welding Protocol (MOST). Available online: http://www.appropedia.org/Laser_welding_protocol: _MOST (accessed on 4 April 2016).

25. Irwin, J.; Pearce, J.M.; Opplinger, D.; Anzalone, G. The RepRap 3-D printer revolution in STEM education. In Proceedings of the 121st ASEE Annual Conference and Exposition, Indianapolis, IN, USA, 15-18 June 2014; Paper ID \#8696.

26. RepRap. Available online: http://reprap.org/wiki/Melzi (accessed on 4 April 2016).

27. Raspberry Pi. Available online: https://www.raspberrypi.org/ (accessed on 4 April 2016).

28. Wijnen, B.; Anzalone, G.C.; Haselhuhn, A.S.; Sanders, P.G.; Pearce, J.M. Free and open-source control software for 3-D motion and processing. J. Open Res. Softw. 2016, 4. [CrossRef] 
29. Github “Franklin”. Available online: https://github.com/mtu-most/franklin (accessed on 15 March 2016).

30. AWWA C105-10 Polyethylene Encasement for Ductile Iron Pipe Systems. Available online: http://awwa. org/store/productdetail.aspx?productid=25362 (accessed on 17 May 2016).

31. Infinity Plastics Datasheet. Available online: http://www.infinityplastics.net/downloads/PollyWrap.pdf (accessed on 17 May 2016).

32. ASTM International. Standard Test Method for Tensile, Compressive, and Flexural Creep and Creep-Rupture of Plastic; ASTM Test Method D2990-01 (Superseded by ASTM Test Method D2009-09); ASTM: West Conshohocken, PA, USA, 2001.

33. ASTM International. Standard Test Method for Tensile Properties of Plastics; ASTM Test Method D638-02a (Superseded by ASTM Test Method D838-14); ASTM: West Conshohocken, PA, USA, 2002.

34. Rasband, W.S. ImageJ; U.S. National Institues of Health: Bethesda, MD, USA, 1997-2015; Available online: http:/ /imagej.nih.gove/ij/ (accessed on 17 March 2016).

35. McGrath, G.C.; Cawley, W.H. Devloping Cost Effective Laser Welding Parameters for Weldable Resins and Application to the Medical Segment. Available online: http://www.clearweld.com/edufiles/ Developing\%20Cost\%20Effective\%20Laser\%20Welding\%20Parameters\%20For\%20Weldable\%20Resins\% 20And\%20Application\%20To\%20The\%20Medical\%20Segment.pdf (accessed on 20 March 2016).

36. Denkenberger, D.; Parisi, M.; Pearce, J.M. Towards low-cost microchannel heat exchangers: Vehicle heat recovery ventilator prototype. In Proceedings of the 10th International Conference on Heat Transfer, Fluid Mechanics and Thermodynamics (HEFAT), Orlando, FL, USA, 14-16 July 2014.

37. Ohadi, M.M. Heat transfer enhancement in heat exchangers. ASHRAE J. 1991, 33, 6-50.

38. Denkenberger, D.C.; Pearce, J.M. Compound parabolic concentrators for solar water heat pasteurization: Numerical simulation. In Proceedings of the 2006 International Conference of Solar Cooking and Food Processing, Granada, Spain, 12-16 July 2006; p. 108.

39. Amanat, N.; James, N.L.; McKenzie, D.R. Welding methods for joining thermoplastic polymers for the hermetic enclosure of medical devices. Med. Eng. Phys. 2010, 32, 690-699. [CrossRef] [PubMed]

40. Khan Malek, C.G. Laser processing for bio-microfluidics applications (part II). Anal. Bioanal. Chem. 2006, 385, 1362-1369. [CrossRef] [PubMed]

41. Coelho, J.P.; Abreu, M.A.; Pires, M.C. High-speed laser welding of plastic films. Opt. Lasers Eng. 2000, 34, 385-395. [CrossRef]

42. Trapani, K.; Redón Santafé, M. A review of floating photovoltaic installations: 2007-2013: A review of floating photovoltaic installations. Prog. Photovolt: Res. Appl. 2015, 23, 524-532. [CrossRef]

43. Pringle, A.M.; Handler, R.R.; Pearce, J.M. Aquavoltaics: Synergies for Dual Use of Water Area for Solar Photovoltaic Electricity Generation and Aquaculture. 2016. under review.

44. Trapani, K. Flexible Floating Thin Film Photovoltaic (PV) Array Concept for Marine and Lacustrine Environments. Doctoral Dissertation, Laurentian University of Sudbury, Sudbury, CA, USA, 16 May 2014. Available online: https:/ / zone.biblio.laurentian.ca/dspace/handle/10219/2199 (accessed on 25 May 2016).

45. Pearce, J.M.; Lau, A. Net energy analysis for sustainable energy production from silicon based solar cells. ASME 2002, 181-186. [CrossRef]

46. Kim, H.C.; Fthenakis, V.; Choi, J.K.; Turney, D.E. Life cycle greenhouse gas emissions of thin-film photovoltaic electricity generation. J. Ind. Ecol. 2012, 16 (Suppl. 1), S110-S121. [CrossRef]

(C) 2016 by the authors; licensee MDPI, Basel, Switzerland. This article is an open access article distributed under the terms and conditions of the Creative Commons Attribution (CC-BY) license (http://creativecommons.org/licenses/by/4.0/). 